\title{
Peripheral Nerves in Early Experimental Diabetes
}

\author{
Expansion of the Endoneurial Space as a Cause of Increased Water Content
}

\author{
J. Jakobsen \\ University Institute of Pathology and Second University Clinic of Internal Medicine, Kommunehospitalet, Aarhus, Denmark
}

\begin{abstract}
Summary. The aim of the present study was to examine whether the nerve water content and the Schwann cell cytoplasm are increased in early experimental diabetes, as suggested in the sorbitol theory. The sciatic nerves of streptozotocin diabetic rats were found to have an increased wet weight. The amount of Schwann cell cytoplasm was reduced by $30 \%$. The increased wet weight was paralleled by enlargement of the cross sectional area of the nerve which was explained by an expansion of the endoneurial space. The findings indicate the existence of endoneurial oedema and are in part in conflict with the sorbitol theory. Extension of the space surrounding the nerve fibres may explain the increased resistance to ischaemia in diabetic patients.
\end{abstract}

Key words: Streptozotocin diabetes, diabetic neuropathy, peripheral nerves, ultrastructure, Schwann cells, endoneurium.

Histological studies in diabetic neuropathy have demonstrated loss of myelin sheaths, particularly segmental demyelination [1]. Consequently some of the biochemical alterations known to occur in diabetic nerves have been thought to be localized within the Schwann cell. For instance, several authors have suggested that increased amounts of sorbitol accumulate within this cell leading to overhydration and swelling [2,3].

In this report on peripheral nerves in streptozotocin diabetic rats the water content of the sciatic nerve and the amount of Schwann cell cytoplasm have been assessed.

\section{Methods}

Male Wistar rats, 24-26 weeks old, weighing between 350 and $450 \mathrm{~g}$, were injected intravenously with $40-45 \mathrm{mg}$ streptozotocin per $\mathrm{kg}$ body weight. Within $24 \mathrm{~h}$ after the injection all animals used in the experiment had a blood glucose above $250 \mathrm{mg} / 100 \mathrm{ml}$, when measured with an Ames Reflectance Meter ${ }^{\circledR}$. Since urine output varies with glucose excretion, $24 \mathrm{~h}$ urine output was followed during the next weeks. In insulin treated rats blood glucose was determined daily at noon with the reflectance meter.

The following control groups were used: a normal control group of age and weight matched animals (control group 1); a group of animals fed a restricted diet leading to a weight loss comparable to that of the diabetic animals (control group 2); and a group of 24 week old rats to measure the changes of nerve weight in control rats between the age of 24 weeks and of 30 weeks (control group 3). Another group of diabetic animals was treated with a long-acting insulin preparation (modified Ultralente, $\mathrm{pH}$ 5.5) given by Dr.J. Schlichtkrull, Novo Research Institute.

The insulin dose was selected according to the blood glucose determinations. Four to ten i. u. per $24 \mathrm{~h}$ were given during the first week and two to five i. u. per day during the next three weeks. The average of the blood glucose values just before the daily insulin injection was $102 \mathrm{mg}$ per $100 \mathrm{ml}$. The last insulin dose was given the day before sacrifice and the mean blood glucose had risen to $303 \mathrm{mg}$ per $100 \mathrm{ml}$ when the rats were killed.

The present report also includes an electron microscopic investigation of nerve specimens which were used for an earlier light microscopic study 
$[4,5,6]$. The male Wistar rats used in this part of the present study were injected intravenously with 40-45 mg streptozotocin per $\mathrm{kg}$ body weight at the age of 19-20 weeks. The diabetes duration was four weeks, blood glucose ranged between 300 and $600 \mathrm{mg}$ per $100 \mathrm{ml}$ and the mean $24 \mathrm{~h}$ urine output was $120 \mathrm{ml}$.

\section{Water Content}

After 4 to 5 weeks the animals were killed. The hind legs were fully extended and the sciatic nerves in the thigh were dissected from the surrounding connective tissues. At a constant site of the sciatic nerve just below the distal edge of the tendon of the obturator externus muscle $1.5 \mathrm{~cm}$ were measured with callipers and removed. The nerve wet weight was determined immediately after removal and the length of time between death and weighing or fixation of the nerves was from 3 to $5 \mathrm{~min}$.

Dry weights were determined after dessiccation at $110^{\circ} \mathrm{C}$ to constant values. The water content was obtained as the difference between wet and dry weights and expressed as $\mathrm{mg}$ water per $\mathrm{cm}$ sciatic nerve.

The brain and the spinal cord were also examined to see whether changes of water content occurred in the central nervous system. The medulla oblongata was cut just below the uvula and the cord between the first and second lumbar vertebrae. Meninges, olfactory bulbs and the paraflocculi were removed before weighing.

\section{Light Microscopy}

Morphological studies were performed on the contralateral sciatic nerve. To avoid errors due to shrinkage during the dehydration procedure 10 to $15 \mu \mathrm{m}$ thick frozen sections of osmium-fixed nerves were cut. The nerves were suspended in $2 \%$ osmium tetroxide (buffer osmolality, 294-299 mosmol/l) for four hours with small weights attached to preserve the nerve length during fixation.

The cross sections were examined by light microscopy using screen projection. The fascicular area and the area of the epi- and perineurium were estimated by point counting at a magnification of 158 $\times$, employing a grid with a point density of 100 points per $2.5 \mathrm{~mm}^{2}$. The grid was placed three times at random on the nerve profile. The fraction of the fascicular area occupied by myelinated fibres was determined at a magnification of $1720 \times$ in three fields using a point density of 1 point per $211 \mu \mathrm{m}^{2}$ and a total of 576 points were counted on each nerve profile at this magnification.
The cross sectional area of all myelinated fibres was calculated by multiplying the area fraction of myelinated fibres by the total fascicular area. The area between myelinated fibres was the difference between fascicular area and myelinated fibre area.

\section{Electron Microscopy}

The nerves were fixed under controlled pressure by vascular perfusion with aldehydes, postfixed in osmium tetroxide, dehydrated in acetone and embedded in Vestopal.

From the embedded common peroneal nerve a random sample corresponding to about $10 \%$ of the fascicular area was obtained by trimming a small pyramid in a preselected area. Ultrathin sections of the sample were cut on a LKB-Ultratome and stained with uranyl magnesium acetate and lead citrate. Electron microscopy was carried out with a Philips EM 200. The magnification was checked by photographing a carbon grating grid on each film and its average value was $13500 \times$.

The electron micrographs of the selected part of the common peroneal nerve were pasted together to one composite picture representing an average area of $13800 \mu \mathrm{m}^{2}$. A grid with a point density of ten points per $125 \mu \mathrm{m}^{2}$ covering the whole photomontage was superimposed. The number of points falling upon the different profiles were counted and the area fractions were thereby obtained.

Myelin is part of the Schwann cell but in this study it was included in the nerve fibre area. The endoneurial space was divided into four areas including: collagen area, the structureless endoneurial space, vessels and cells (mast cells and fibroblasts). The collagen areas were defined as groups of more than ten microfibrils regularly spaced. The structureless endoneurial space was the area where no cells, vessels or collagen were recognized.

The density of microfibrils in the collagen areas was estimated by counting the number of fibrils in each animal within ten small quadrants under a magnifying glass. Randomized selection of numbered electron micrographs was obtained by means of a table of random numbers and subsequently the areas of collagen in the upper left corner of the selected ten micrographs were chosen for measurements. The midpoint of the grid with the small quadrants of $0.088 \mu \mathrm{m}^{2}$ was superimposed in the middle of the collagen area and the number of microfibrils were counted within the first quadrant covered completely by collagen.

Student's t-test was employed in the statistical treatment. 
Table 1. Light microscopic areas of cross sectioned osmium-fixed non-dehydrated sciatic nerves in rats with a diabetes duration of four weeks and in age-matched controls (control group 1 ). Results are mean values \pm SD

\begin{tabular}{|c|c|c|c|c|}
\hline & $\begin{array}{l}\text { Fascicular area } \\
\mathrm{mm}^{2}\end{array}$ & $\begin{array}{l}\text { Myelinated nerve } \\
\text { fibre area } \\
\mathrm{mm}^{2}\end{array}$ & $\begin{array}{l}\text { Area between myelinated } \\
\text { nerve fibres } \\
\mathrm{mm}^{2}\end{array}$ & $\begin{array}{l}\text { Epi- and } \\
\text { perineurial area } \\
\mathrm{mm}^{2}\end{array}$ \\
\hline $\begin{array}{l}\text { Control } \\
(n=13)\end{array}$ & $0.74 \pm 0.06$ & $0.47 \pm 0.04$ & $0.27 \pm 0.05$ & $0.20 \pm 0.05$ \\
\hline $\begin{array}{l}\text { Diabetes } \\
(n=19)\end{array}$ & $0.83 \pm 0.11$ & $0.43 \pm 0.04$ & $0.39 \pm 0.11$ & $0.18 \pm 0.05$ \\
\hline $2 \mathrm{p}$-value & 0.017 & 0.031 & 0.00029 & n.s \\
\hline
\end{tabular}

nerve wet weight

nerve water content

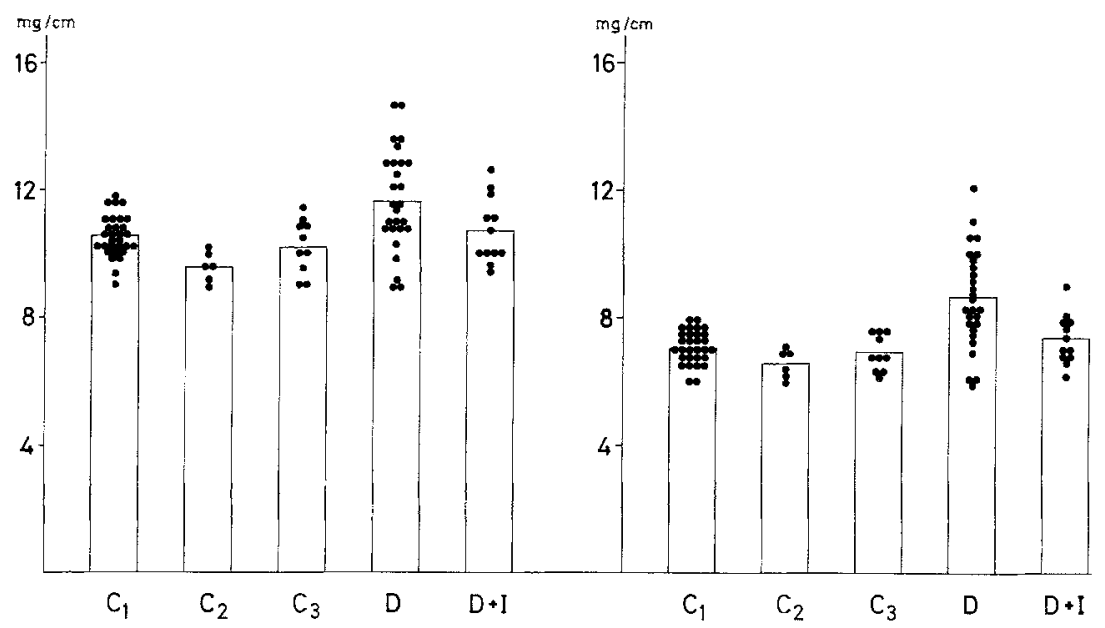

Fig. 1 a and b. Individual wet weight and water content of sciatic nerve in $\mathrm{mg}$ per $\mathrm{cm}$ nerve in each group of rats. The average value of each group is given by the height of the bar. Symbols: $c_{1}=$ age-matched controls $(\mathrm{n}, 30) ; \mathrm{c}_{2}=$ controls with a weight loss comparable to that of the diabetic rats $(n, 6) ; c_{3}=$ controls to estimate nerve weight changes in normal rats during the experiment $(\mathrm{n}, 10) ; \mathrm{D}=$ diabetic rats $(\mathrm{n}, 27) ; \mathrm{D}+\mathrm{I}=$ insulin treated diabetic rats $(n, 12)$

\section{Results}

The streptozotocin diabetic rats all lost weight, the average loss being $63 \mathrm{~g}$ (range, -15 to $-110 \mathrm{~g}$ ) and the $24 \mathrm{~h}$ urine output varied between 40 and $230 \mathrm{ml}$ (mean, $139 \mathrm{ml}$ ).

The insulin treated animals had a slight weight gain of $6 \mathrm{~g}$ (range, -20 to $30 \mathrm{~g}$ ) and the rats of control group 1 also had a slight weight gain (mean, $10 \mathrm{~g}$; range, -5 to $25 \mathrm{~g}$ ).

\section{Water Content}

The wet weights of the sciatic nerves for diabetic rats and controls are shown in Figure $1 \mathrm{a}$. The increase in diabetic rats amounted to $10 \%$ when compared to control group $1,11.7 \pm 1.6 \mathrm{mg} / \mathrm{cm}$ (SD) versus $10.6 \pm 0.7 \mathrm{mg} / \mathrm{cm}(2 \mathrm{p}, 0.002)$. The wet weight of the diabetic nerves was also increased when compared to control groups 2 and 3. For the group of insulin treated animals the average wet weight was the same as that of the normal control group, but statistical analysis did not reveal any difference from the diabetic rats not given insulin $(2 p$, $0.061)$.
The dry weight of the diabetic nerves was 3.0 $\pm 0.3 \mathrm{mg} / \mathrm{cm}$ as compared to $3.5 \pm 0.3 \mathrm{mg} / \mathrm{cm}$ in control group $1(2 \mathrm{p}, 0.0002)$ and $3.4 \pm 0.4 \mathrm{mg} / \mathrm{cm}$ in insulin treated animals $(2 \mathrm{p}, 0.011)$. However, the dry nerve weight in control group 2 and $3(3.0$ $\pm 0.3 \mathrm{mg} / \mathrm{cm}$ and $3.3 \pm 0.3 \mathrm{mg} / \mathrm{cm}$, respectively) did not differ statistically from that of the diabetic animals.

The water content of the nerves is shown in Figure $1 \mathrm{~b}$. The mean value for the diabetic rats was $8.6 \pm 1.5 \mathrm{mg} / \mathrm{cm}$ and for control group 17.1 $\pm 0.5 \mathrm{mg} / \mathrm{cm}$. This difference which amounts to $21 \%$ is significant $(2 \mathrm{p}, 0.000024)$. When the diabetic mean value was compared to the mean values of control groups 2 and 3 and to that of insulin treated rats it was found that these differences were also significant. The water content of the nerves of the insulin treated group was $7.4 \pm 0.8 \mathrm{mg} / \mathrm{cm}$, not different from that of the normal control group.

The relative water content of the nerves from the diabetic rats $(73.6 \pm 4.1 \%)$ was significantly higher than in control group $1(67.1 \pm 1.6 \%)$ as well as in the other three groups (range, $67.7 \%$ to $68.8 \%$ ). 

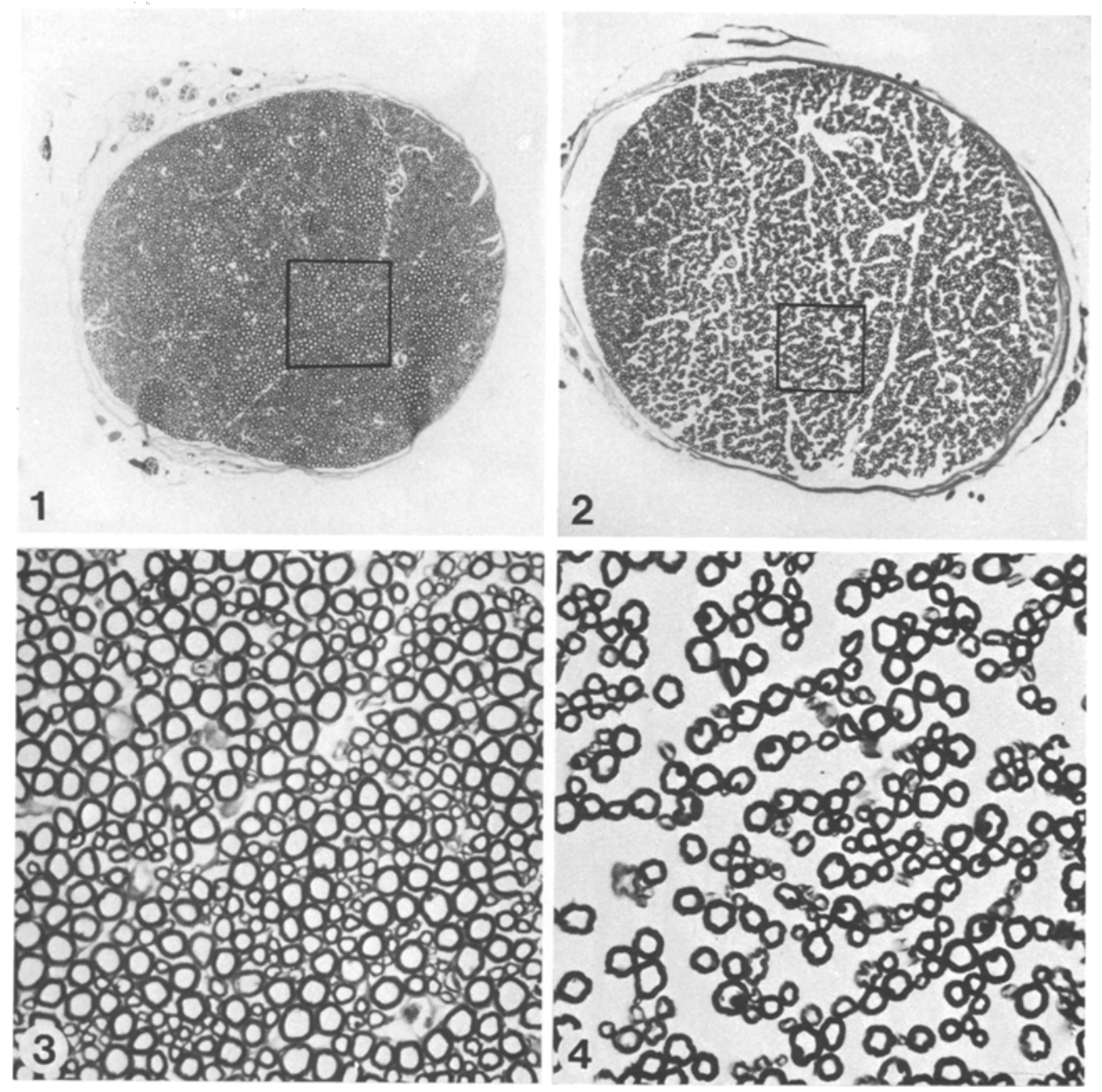

Fig. 2. Micrographs to illustrate severe alterations occurring in a diabetic osmium-fixed non-dehydrated sciatic nerve. The first and second pictures $(\times 45)$ are examples of a control and a diabetic nerve, respectively. The third and fourth picture are higher magnifications $(X 225)$ of 1 and 2 , respectively

The wet weight and the water content of the brains and the wet weight of the cords were similar in the diabetic animals and in the controls. The wet weight of the brains was $1911 \pm 81 \mathrm{mg}(\mathbf{n}, 17)$ in control group 1 and $1853 \pm 108 \mathrm{mg}(\mathrm{n}, 16)$ in the diabetic rats and the relative water content in the two groups was $77.4 \pm 0.2 \%$ and $77.2 \pm 0.4 \%$.

\section{Light Microscopy}

The cross sectional areas of osmium-fixed nondehydrated sciatic nerves are given in Table 1 and illustrated in Figure 2. The fascicular area and the area between myelinated fibres were increased in the nerves from the untreated diabetic animals by 12 and $46 \%$, respectively, whereas the myelinated fibre area was decreased by $8 \%$. There was a positive correlation between the area between myelinated fibres and water content $(r, 0.54 ; 2 p, 0.0014)$.

\section{Electron Microscopy}

The morphometric data of the analysis of the montages of electron micrographs of part of the common peroneal nerve are given in Table 2 .

The absolute areas of the different structures are obtained by multiplying the fractional area of the structure by the cross sectional area of the nerve.

It appears that the cross sectional area of myelinated fibres is decreased in diabetic rats. This is in agreement with the previous light microscopic finding of reduced fibre size in the same rats $[4,5]$.

The area of the Schwann cells surrounding the myelinated nerve fibres was decreased by nearly $30 \%$ in diabetic animals. There was also a decrease in the Schwann cell area of unmyelinated fibres. However, this latter difference was not statistically significant.

In the endoneurial space there was an increased 
Table 2. Absolute and relative ultrastructural areas of cross sectioned common peroneal nerves in rats with a diabetes duration of four weeks and in age-matched controls. Results are mean values $\pm \mathrm{SD}$

\begin{tabular}{|c|c|c|c|c|c|c|c|}
\hline & & \multicolumn{3}{|c|}{ Relative areas percent } & \multicolumn{3}{|c|}{ Absolute areas $\mu \mathrm{m}^{2} \times 10^{3}$} \\
\hline & & $\begin{array}{l}\text { Control } \\
(\mathrm{n}=10)\end{array}$ & $\begin{array}{l}\text { Diabetes } \\
(\mathrm{n}=10)\end{array}$ & $2 p$-value & $\begin{array}{l}\text { Control } \\
(\mathrm{n}=10)\end{array}$ & $\begin{array}{l}\text { Diabetes } \\
(\mathrm{n}=10)\end{array}$ & $2 \mathrm{p}$-value \\
\hline \multirow{4}{*}{ 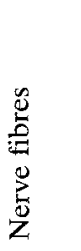 } & Myelinated fibres & $68.1 \pm 4.1$ & $58.0 \pm 5.8$ & 0.00028 & $87.5 \pm 11.1$ & $75.8 \pm 7.7$ & 0.013 \\
\hline & $\begin{array}{l}\text { Schwann cells of } \\
\text { myelinated fibres }\end{array}$ & $8.0 \pm 1.4$ & $5.7 \pm 1.0$ & 0.00052 & $10.3 \pm 2.1$ & $7.4 \pm 1.1$ & 0.0014 \\
\hline & Unmyelinated fibres & $1.3 \pm 0.4$ & $1.1 \pm 0.6$ & n.s. & $1.7 \pm 0.6$ & $1.5 \pm 0.7$ & n.s. \\
\hline & $\begin{array}{l}\text { Schwann cells of } \\
\text { unmyelinated fibres }\end{array}$ & $1.2 \pm 0.4$ & $0.9 \pm 0.4$ & 0.091 & $1.6 \pm 0.5$ & $1.2 \pm 0.4$ & 0.077 \\
\hline \multirow{4}{*}{ 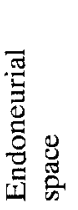 } & Collagen & $12.9 \pm 1.0$ & $15.1 \pm 3.1$ & 0.059 & $16.5 \pm 1.5$ & $20.2 \pm 5.9$ & 0.092 \\
\hline & $\begin{array}{l}\text { Structureless } \\
\text { endoneurial space }\end{array}$ & $5.2 \pm 3.4$ & $16.8 \pm 5.2$ & 0.000015 & $6.6 \pm 4.4$ & $22.5 \pm 7.9$ & 0.000028 \\
\hline & Vessels & $2.7 \pm 2.3$ & $1.7 \pm 1.9$ & n.s. & $3.3 \pm 2.9$ & $2.2 \pm 2.4$ & n.s. \\
\hline & Cells & $0.6 \pm 0.3$ & $0.7 \pm 0.2$ & n.s. & $0.7 \pm 0.5$ & $1.0 \pm 0.4$ & n.s. \\
\hline
\end{tabular}

cross sectional area of collagen in diabetic rats. This is probably due to a decreased density of microfibrils $\left(26.5 \pm 7.0\right.$ per $0.1 \mu \mathrm{m}^{2}$ in diabetic rats and $35.3 \pm 4.4$ per $0.1 \mu \mathrm{m}^{2}$ in controls; $2 \mathrm{p}, 0.0049$ ). The cross sectional area of the structureless space is shown for each rat in Figure 3. In the diabetic rats a 3-4 fold increase of this area was seen. Figure 4 illustrates the increase in the endoneurial space.

\section{Discussion}

These experiments have demonstrated that diabetic nerves are heavier and have an enlarged cross sectional area. The weight change is due to an increase of the water content which correlates with the area between the myelinated fibres. Since the increase of the water content could be prevented by insulin treatment it seems unlikely that the changes of the present study are induced by a toxic effect of streptozotocin itself.

Gabbay (1973) found a normal water content in sciatic nerves from rats after four weeks of diabetes [7]. However, the diabetic animals used in that study served as a control group and the information about these animals and the dessication method is sparse. Therefore it is difficult to comment further on the disparity between these two studies. Systematic differences in water estimation are unlikely because the relative water content of nondiabetic nerves found in this study $(67.1 \%)$ is very close to that found by Gabbay (70.6\%) and by Majno and Karnovsky [8] (69\%). These latter authors used the same dessication procedure used in the present experiments.

All the methods used for the preparation of his- structureless endoneurial space

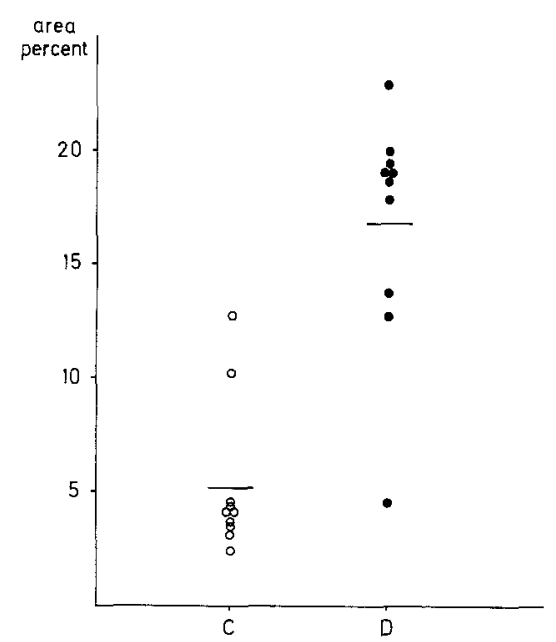

Fig. 3. Area fractions of the common peroneal nerve occupied by the structureless endoneurial space in each of ten age-matched controls $(O)$ and in ten diabetic animals $(\bullet)$

tological sections (freezing, fixation, dehydration and embedding) may induce swelling, shrinkage or distortion of tissue. Therefore some caution must be exercised when dealing with volumes of tissues prepared by histological techniques. However, the results here obtained by different methods do favour the existence of an endoneurial oedema.

A special problem of histological preparation of diabetic tissue is the increased tissue osmolality. As the osmolality of diabetic tissue in the present experiment probably was increased by the same $5 \%$ as that of the serum the tissues might swell during fixation. However, the finding of an important enlargement of the endoneurial space cannot be explained by such a small osmotic difference. 

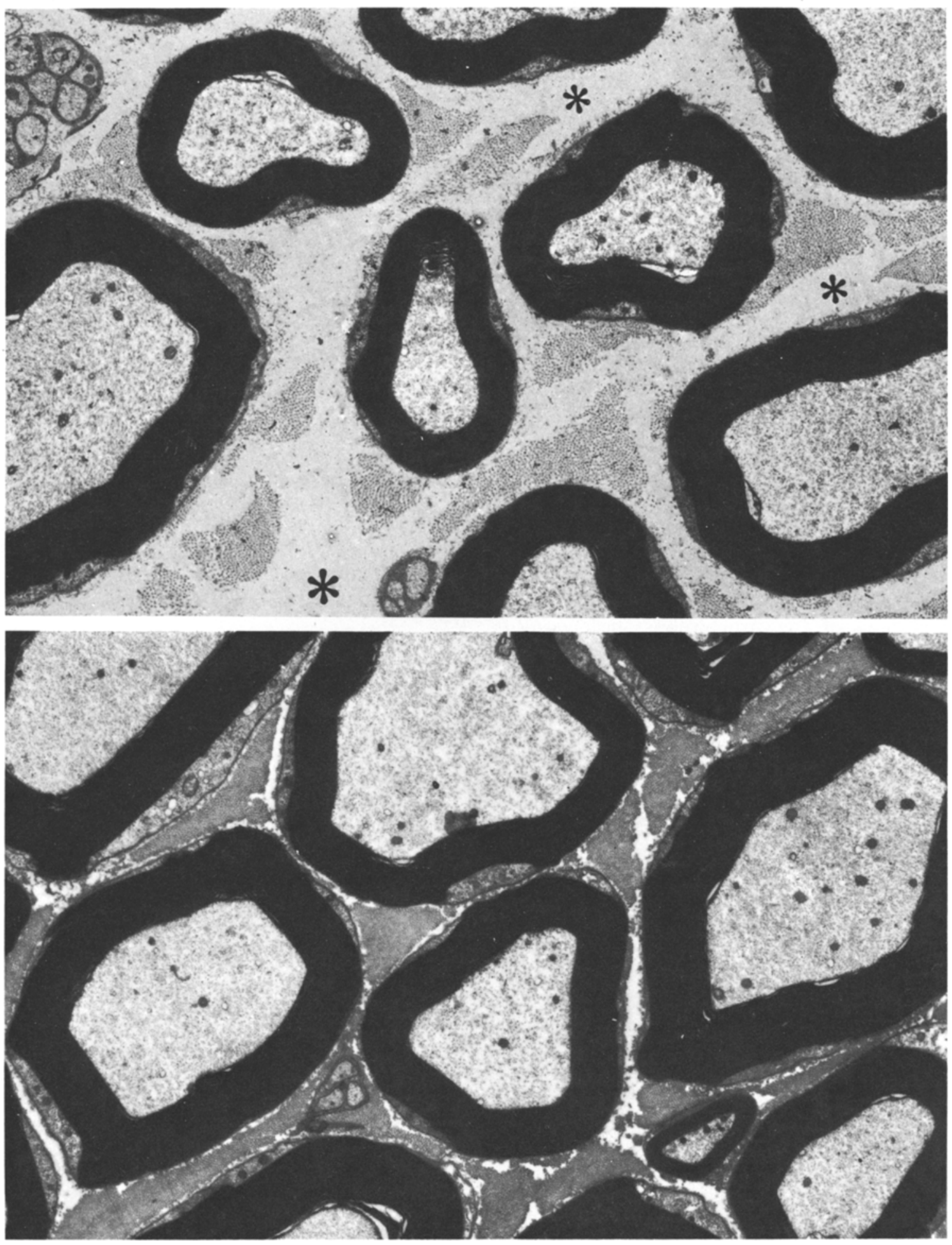

Fig. 4. Electron micrographs $(\times 6,000)$ of part of the common peroneal nerve in a diabetic rat with severe changes (upper micrograph) and in an age-matched control. Asterix are placed in the structureless endoneurial space

The present observation of a $30 \%$ shrinkage of the Schwann cell is in conflict with part of the sorbitol theory. In transection studies, where axons disappear and Schwann cells proliferate, the content of the enzyme aldose reductase converting glucose to sorbitol was found to be increased [2]. Therefore, it was assumed that sorbitol is produced within the Schwann cell. Since sorbitol penetrates cell membranes slowly [9] it has been suggested that the increased amount in peripheral nerves in diabetes is located within this cell giving rise to osmotic swelling [2]. 
Although the shrinkage of the Schwann cells observed in this study was observed on electron micrographs of dehydrated tissue, it seems unlikely that significant swelling of these cells occurs.

It is worth noticing that Gabbay (1968) found a $30 \%$ decrease of the enzyme aldose reductase in alloxan diabetic rats [2]. This reduction was suggested to be due to a segmental demyelination process resulting in damage and loss of some Schwann cells while others are saved. However, from studies of isolated nerve fibres it appears that demyelination does not occur in diabetic rats $[6,10]$. According to the results obtained in the present paper the reduction of the aldose reductase may be better explained by the shrinkage of the Schwann cell.

It is obvious from the electron microscopic examination that the endoneurial space is enlarged. This enlargement is partly brought about by an increase of the structureless endoneurial space and partly by a widening of the distance between the collagen microfibrils. At present the cause of this oedema is unknown but two suggestions are offered.

Since fructose and sorbitol are known to accumulate in peripheral nerves in experimental diabetes $[2,3]$ it could be that this accumulation occurs in the endoneurial space and thereby produces overhydration. However, there is evidence that fructose and sorbitol are produced within the nerve fibres and their Schwann cells, and also that the penetration of these substances through cell membranes is slow $[2,9]$. Furthermore one would expect that small organic molecules such as sugar alcohols would easily diffuse from the endoneurial space through the endothelial lining into the circulation.

Another explanation for the endoneurial oedema could be that the intraneural capillaries become more permeable in diabetics allowing small protein molecules to escape and hence increase the osmotic pressure of the intercellular tissues producing oedema. In fact an increased permeability of the bloodnerve barrier in sciatic nerves of alloxan diabetic rats was reported by Seneviratne (1972) using an albumin-Evans blue conjugate as a fluorescent tracer in a light microscopic examination [11].

In a recent study of Sharma, Thomas and Baker (1976) [12] on peripheral nerves of galactose-fed rats morphological changes very similar to those occurring in streptozotocin diabetic rats are reported. After galactose feeding rats were found to have an increased water content and fascicular area together with a slight reduction of fibre diameter. On the basis of these findings the authors suggested that an expansion of the endoneurial tissue compartment had occurred.

The endoneurial oedema may explain the prolonged resistance of nerve action to ischaemia as ob- served regularly in diabetic patients $[13,14,15]$. If the endoneurial space is larger also in human beings suffering from diabetes mellitus it is possible that an endoneurial potassium concentration sufficiently high to depolarize the axonal membrane and block the conduction can be obtained only after a longer period of ischaemia ${ }^{1}$.

\footnotetext{
Acknowledgement. This idea was first suggested by Troels Kardel in March 1977 during the discussion in the Danish Society of Internal Medicine of the results presented here
}

\section{References}

1. Thomas, P.K., Lascelles, R.G.: Schwann-cell abnormalities in diabetic neuropathy. Lancet 1965 I, 1355-1357

2. Gabbay, K.H., O'Sullivan, J.B.: The sorbitol pathway. Enzyme localization and content in normal and diabetic nerve and cord. Diabetes 17, 239-243 (1968)

3. Gabbay, K.H.: The sorbitol pathway and the complications of diabetes. N. Engl. J. Med. 288, 831-836 (1973)

4. Jakobsen, J., Lundbæk, K.: Neuropathy in experimental diabetes: An animal model. Br. Med. J. 1976 II, 278-279

5. Jakobsen, J.: Axonal dwindling in early experimental diabetes. I. A study of cross sectioned nerves. Diabetologia 12, 539-546 (1976)

6. Jakobsen, J.: Axonal dwindling in early experimental diabetes. II. A study of isolated nerve fibres. Diabetologia 12, 547-553 (1976)

7. Gabbay, K.H.: Role of sorbitol pathway in neuropathy. In: R.A. Camerini-Dávalos, H.S. Cole, (eds.): Vascular and neurological changes in early diabetes. Advances in metabolic disorders, Suppl. 2, pp. 417-429. New York, London: Academic Press 1973

8. Majno, G., Karnovsky, M.L.: A biochemical and morphologic study of myelination and demyelination. I. Lipid biosynthesis in vitro by normal nervous tissue. J. Exp. Med. 107, 475-496 (1958)

9. LeFevre, P.G., Davies, R.I.: Active transport into the human erythrocyte: Evidence from comparative kinetics and competition among monosaccharides. J. Gen. Physiol. 34, 515-524 (1951)

10. Sharma, A.K., Thomas, P.K.: Peripheral nerve structure and function in experimental diabetes. J. Neurol. Sci. 23, 1-15 (1974)

11. Seneviratne, K.N.: Permeability of blood nerve barriers in the diabetic rat. J. Neurol. Neurosurg. Psychiatry 35, 156-162 (1972)

12. Sharma, A.K., Thomas, P.K., Baker, R.W.R.: Peripheral nerve abnormalities related to galactose administration in rats. J. Neurol. Neurosurg. Psychiatry 39, 794-802 (1976)

13. Steiness, I.: Vibratory perception in diabetics during arrested blood flow to the limb. Acta Med. Scand. 163, 195-205 (1959)

14. Gregersen, G.: A study of the peripheral nerves in diabetic subjects during ischaemia. J. Neurol. Neurosurg. Psychiatry 31, 175-181 (1968)

15. Seneviratne, K.N., Peiris, O.A.: The effects of hypoxia on the excitability of the isolated peripheral nerves of alloxan-diabetic rats. J. Neurol. Neurosurg. Psychiatry 32, 462-469 (1969)

Received: May 12, 1977, and in revised form: August 11, 1977

Dr. J. Jakobsen

Second University Clinic of Internal Medicine

Kommunehospitalet

DK-8000 Aarhus, Denmark 